This work was assessed during the iGEM/PLOS Realtime Peer Review Jamboree on $23^{\text {rd }}$ February 2018 and has been revised in response to the reviewers' comments. A transcript of these comments is available with the original article as a supplementary file.

\title{
SUMO-based expression and purification of dermcidin-derived DCD-1L, a human antimicrobial peptide, in Escherichia coli
}

Authors

Ushanandini Mohanraj, B.Tech* (1), Oona Kinnunen B.Sc. (2), Meryem Ecem Kaya, B.Sc.

(2), Aino Sesilja Aranko, PhD (3), Heli Viskari, PhD (3), Markus Linder, PhD (3)

Affiliations

(1) Faculty of Medicine, University of Helsinki, Helsinki, Finland

(2) Faculty of Biological and Environmental Sciences, University of Helsinki, Helsinki, Finland

(3) Department of Bioproducts and Biosystems, School of Chemical Engineering, Aalto University, Kemistintie 1D, 02150 Espoo, Finland

*Corresponding author: Ushanandini Mohanraj (ushanandini.mohanraj@helsinki.fi)

Author contributions

Conceptualization: Ushanandini Mohanraj, Oona Kinnunen, Meryem Ecem Kaya.

Methodology: Ushanandini Mohanraj, Oona Kinnunen, Meryem Ecem Kaya, Aino Sesilija Aranko.

Investigation: Ushanandini Mohanraj, Oona Kinnunen, Meryem Ecem Kaya.

Writing: Ushanandini Mohanraj, Oona Kinnunen, Meryem Ecem Kaya.

Funding Acquisition: Heli Viskari, Markus Linder.

Supervision: Aino Sesilija Aranko, Heli Viskari, Markus Linder.

\begin{abstract}
The dermcidin-derived peptide DCD-1L has a broad spectrum of antimicrobial activity over a wide $\mathrm{pH}$ range and in high salt concentrations. Thus, it offers a promising alternative to conventional antibiotics. Furthermore, it plays a role in wound healing, atopic dermatitis and acne vulgaris, indicating applications in cosmetic industries. Recently, dermcidin has been identified as a tumor marker improving cancer prognosis. Hence, large quantities of purified DCD-1L peptide are required to meet the needs of basic research and clinical trials. In the current study, we demonstrate SUMO-based heterologous DCD-1L production in Escherichia coli, followed by affinity chromatography purification. The SUMO tag is cleaved with SUMOspecific protease following purification, leaving free DCD-1L peptide without any additional amino acids. The mass of the peptide was further confirmed by MALDI-TOF-TOF analysis. Furthermore, the cleaved DCD-1L showed antimicrobial activity against the E. coli DH5 alpha test strain. The production and purification of DCD-1L using SUMO tag compare advantageously to other protocols previously described. Thus, the SUMO tag system enables large scale recombinant production of the antimicrobial peptide DCD-1L, which constitutes pharmaceutical and therapeutic potential as an alternative antibiotic.
\end{abstract}




\section{Financial Disclosure}

1) The project was funded by Aalto University and HiLIFE- Helsinki Institute of Life Science

2) The funders had no role in study design, data collection and analysis, decision to publish, or preparation of the manuscript.

\section{Competing Interests}

The authors have declared that no competing interests exist.

\section{Ethics Statement}

N/A

\section{Data Availability}

All relevant data are within the paper.

\section{Introduction}

New alternatives to antibiotics have received great attention due to an increasing threat of antibiotic resistance to commonly used antibiotics. Antimicrobial peptides emerge as a promising alternative due to their wide range of activity spectrum. Since the 70's, several antimicrobial peptides from various species have been discovered. Antimicrobial peptides are known for their important role in natural self-defense mechanism for many species, including bacteria, fungi, and primates. Three important groups of human antimicrobial peptides that have been widely reported include defensins, histatins and cathelicidin. The third group comprises only one antimicrobial peptide, the cathelicidin LL-37. All three families of peptides are cationic in nature and they act by electrostatic interactions with the negatively charged phospholipid bilayer of pathogens (Smet et al., 2005). However, in 2001, a new anionic defense peptide called dermcidin was discovered in primates with no homology to other known AMPs (Schittek et al., 2001). Unlike human defensins and cathelicidins that are induced under inflammatory and injured conditions, dermcidin is constitutively expressed in human sweat (Rieg et al, 2004). The prevalent model for the structural basis of DCD-1L action is that it forms pores in the bacterial membrane leading to cell death (Paulmann et al, 2012).

Dermcidin is secreted to epidermal surface as a part of the first line of defense (Burian and Schittek, 2015). The dermcidin precursor is 110 amino acids long, and it includes a 19-aminoacid long signal peptide. Once the antimicrobial peptide precursor is secreted with sweat to the epidermal surface, the signal peptide is cleaved, and the precursor undergoes further proteolytic processing leading to formation of several dermcidin-derived peptides (Paulmann et al, 2012). Among these, DCD-1L is one of the most abundant dermcidin-derived peptides (Steffen et al., 2006). It is a 48-amino-acid long anionic peptide and it has an overall net charge of -2 with a cationic N-terminal region and an anionic C-terminal region (Paulmann et al., 2012, Steffen et al., 2006). DCD-1L is active against a wide range of pathogens including Gram-positive (Staphylococcus aureus, Enterococcus faecalis, Staphylococcus epidermidis, 
Listeria monocytogenes) and Gram-negative bacteria (Escherichia coli, Pseudomonas putida, Salmonella typhimurium) as well as Candida albicans (Steffen et al., 2006).

Dermcidin has evolved to survive and maintain its activity under a range of different $\mathrm{pH}$ and salt conditions that are characteristic of human sweat, which makes it possible to use it for a wide range of applications. It has been observed that wound healing is significantly impaired during reduced hBD-2 and DCD expression in burn wounds, which may explain the increased susceptibility to infection and sepsis in burn patients (Milner and Ortega, 1999). Furthermore, a significant reduction of DCD-derived peptides has been witnessed in the atopic dermatitis patients who encounter recurrent bacterial or viral infections and pronounced colonization with Staphylococcus aureus (Rieg et al., 2005). Also, the expression of DCD is downregulated in the sweat of patients with acne vulgaris, suggesting a deficiency in the constitutive innate defense (Nakano et al., 2015).

Due to the wide host range of dermcidin and its pharmaceutical and therapeutic potential, a cost-effective and scalable method for DCD-1L production is required. In the present work, we describe the successful cloning, expression and purification of DCD-1L using Smt3 as fusion partner without any additional residues and have demonstrated its activity. Employing SUMO tag is beneficial during primary purification step due to its positive effect on protein solubility. Further it also prevents the formation of inclusion bodies of the fusion proteins. SUMO is a highly conserved family of proteins in eukaryotes and is absent from prokaryotes (Malakhov et al., 2004). These proteins belong to a group of ubiquitin-like proteins due to their shared structural homology with ubiquitin. SUMO tags can be cleaved by using SUMO-specific proteases Ulp1 and Ulp2 in yeast, and SENP1 and SENP2 in humans (Yan et al., 2009). These proteases recognize SUMO through tertiary interactions and cleave it at the C-terminus (Malakhov et al., 2004). We have utilized Ulp1 enzyme in our work to cleave off the His6xSmt3 tag that is used in expression and purification. The His6x tag in the N-terminus is used for purification with immobilized metal ion affinity chromatography columns designed for histidine-tagged proteins.

\section{Materials and Methods}

\subsection{Bacterial strains and plasmids}

Chemically competent Escherichia coli TOP10 cells were used as host for cloning and E. coli T7 express cells were used for gene expression of His6x-Smt3-DCD-1L fusion constructs. $E$. coli was grown at $37{ }^{\circ} \mathrm{C}$ in LB media for cloning and expression, and kanamycin $(50 \mu \mathrm{g} / \mathrm{ml})$ was added to the media during growth of plasmid-containing strains. The vector pET28a $(+)$ (carrying an N-terminal His6x tag and the gene for kanamycin resistance) was used for cloning and expression of the target genes. The vector allows for expression of exogenous proteins and peptides under the control of the T7lac promoter (Novagen, Madison, WI). Vector carrying the Smt3 tag and the pET28a(+) vector were kindly provided by Sesilja Aranko from Aalto University. 


\subsection{Cloning of the DCD-1L expression vector}

Smt3 tag was amplified by PCR from with forward primer 5'TATCATATGGGATCGGACTCAGAAGTC-3' (NdeI restriction site underlined) and reverse primer 5'-TGATCTCGAGTTAGGATCCACCAATCTGTTC-3' (XhoI restriction site in bold; BamHI restriction site underlined). The PCR product was ligated into the vector pET28a $(+)$ restricted with NdeI and XhoI restriction enzymes to obtain the plasmid pET28a(+)Smt3.

The following DNA construct (for DCD-1L) was ordered from Integrated DNA Technologies (IDT) as a gBlock:

5'-

AACGGATCCAGCCTGCTGGAAAAAGGCCTGGATGGCGCGAAAAAAGCGGTGGG CGGCCTGGGCAAACTGGGCAAAGATGCGGTGGAAGATCTGGAAAGCGTGGGCA AAGGCGCGGTGCATGAT-3' (BamHI restriction site underlined; XhoI restriction site in bold)

The DCD-1L gBlock from IDT was prepared according to the IDT instructions. DNA was dissolved in TE buffer (10 mM Tris; $0.1 \mathrm{mM}$ EDTA; $\mathrm{pH} 8,0)$ at $10 \mathrm{ng} / \mu \mathrm{l}$ final concentration. Then the gBlock was ligated into the vector pET28a(+)-Smt3 restricted with BamHI (NEB) and XhoI (NEB) to obtain the plasmid pET28a(+)-Smt3-DCD-1L (Figure 1)

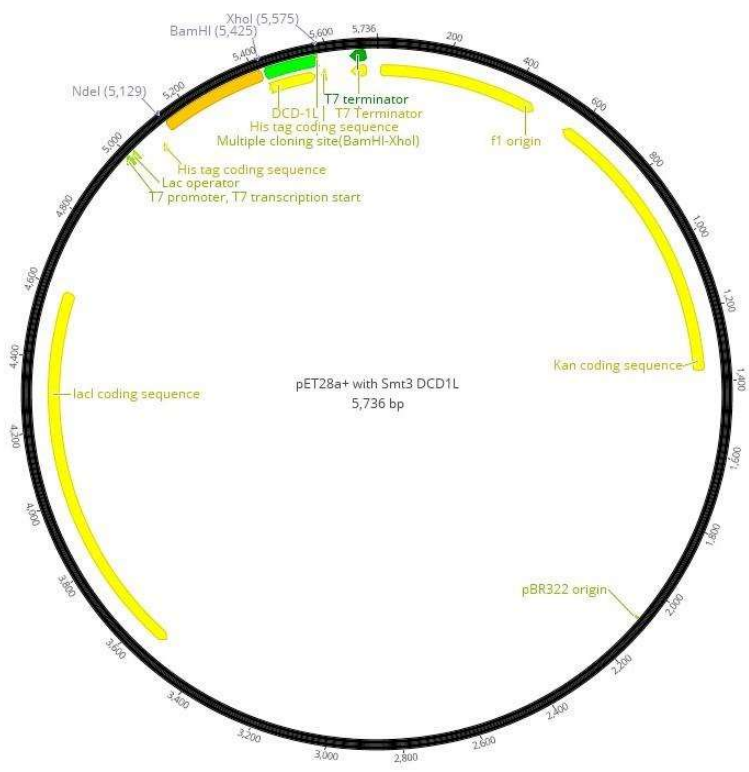

Figure 1. Plasmid map of Smt3-DCD-1L (Geneious version 10.1.3 [Kearse et al., 2012]).

Standard heat-shock transformation protocol was performed. Plates were incubated at $37{ }^{\circ} \mathrm{C}$ for over 12 hours before selecting kanamycin-resistant transformants for plasmid isolation, which was performed according to the manual of high copy number plasmid isolation in the Macherey-Nagel Nucleospin Plasmid kit. To verify that the isolated plasmids carried the desired insert, check-up digestion of the plasmids was performed using NdeI and XhoI 
restriction enzymes. Plasmids that carried an insert of the correct size were sent for sequencing at Eurofins Genomics, using the available sequencing primer T7 term (5'CTAGTTATTGCTCAGCGGT-3').

\subsection{Small-scale expression and purification of DCD-1L}

For small-scale production, T7 Express Competent E. coli were transformed with cloned plasmids by heat-shock transformation. 3-4 colonies were inoculated in $7 \mathrm{ml}$ of LB-kanamycin $\left(50 \mu \mathrm{g} / \mathrm{ml}\right.$ working concentration). The cultures were incubated at $37{ }^{\circ} \mathrm{C}$ in shaking flasks. Expression of the construct was induced at an OD600 of $\sim 0.5$ with addition of IPTG at a final concentration of $0.5 \mathrm{mM}$. Cells were harvested 4 hours after the induction by centrifuging at $12,000 \times \mathrm{g}$ for 1 minute. The pellet was resuspended in $100 \mu \mathrm{l}$ of ThermoFisher Scientific BPER Bacterial Protein Extraction Reagent. After equilibrating the Qiagen Ni-NTA spin columns with NPI-10 buffer ( $50 \mathrm{mM} \mathrm{NaPi}, 300 \mathrm{mM} \mathrm{NaCl}, \mathrm{pH} 8.0)$, protein purification was performed. Samples were loaded onto the spin columns and centrifuged at 1,600 rpm for 5 minutes, followed by washing the columns with NPI-20 buffer $(50 \mathrm{mM} \mathrm{NaPi}, 300 \mathrm{mM} \mathrm{NaCl}$, $30 \mathrm{mM}$ imidazole, $\mathrm{pH} 8.0)$. Proteins were eluted in NPI-500 buffer (50 mM NaPi, $300 \mathrm{mM}$ $\mathrm{NaCl}, 250 \mathrm{mM}$ imidazole, $\mathrm{pH}$ 8.0). The used spin columns were soaked in $0.1 \mathrm{M}$ EDTA solution and stored at $4{ }^{\circ} \mathrm{C}$. Different flow-throughs and elution fractions were then analysed on $15 \%$ SDS-PAGE gel. The PageRuler ${ }^{\mathrm{TM}}$ Prestained Protein Ladder (ThermoFisher) was used in this and other SDS-PAGE analyses. Gels were stained with Coomassie Blue and imaged with Bio-Rad Gel Doc ${ }^{\mathrm{TM}} \mathrm{XR}+$ imager and Image Lab software (version 5.1). During purification, elution fractions were collected. Fractions containing the protein of interest were stored for further experiments.

\subsection{Larger Scale expression and purification of DCD-1L}

For larger scale expression, T7 Express Competent E. coli were transformed with cloned plasmids by heat-shock transformation. Kanamycin-resistant transformants were pre-cultured in LB medium with $50 \mu \mathrm{g} / \mathrm{ml}$ kanamycin at $30^{\circ} \mathrm{C}$ overnight. The following day the pre-culture was diluted 1:100 with fresh LB-kanamycin medium and grown at $37^{\circ} \mathrm{C}$ until OD600 value reached 0.6. Protein expression was induced with IPTG at a final concentration of $0.5 \mathrm{mM}$. Cells were harvested 4 hours after induction of protein expression by centrifuging in ThermoScientific Sorvall Lynx 4000 centrifuge at 5,000 x g for 10 minutes at $16^{\circ} \mathrm{C}$ with the rotor F10-4x1000 LEX. Pellet was resuspended in Buffer A $(50 \mathrm{mM} \mathrm{NaPi}, 300 \mathrm{mM} \mathrm{NaCl}, \mathrm{pH}$ 8.0 ) and frozen in liquid nitrogen before storing at $-20^{\circ} \mathrm{C}$.

Frozen cells were thawed in water bath before lysing them with EmulsiFlex-C3. Lysed cells were centrifuged in ThermoScientific Sorvall Lynx 4000 centrifuge at $18,000 \mathrm{x}$ g for 30 minutes at $4{ }^{\circ} \mathrm{C}$ with the rotor F20-12x50 LEX. Supernatant was purified with GE Healthcare Life Sciences ÄKTA pure using the GE Healthcare Life Sciences HisTrap ${ }^{\mathrm{TM}}$ FF crude $5 \mathrm{ml}$ column. The proteins were eluted with Buffer B $(50 \mathrm{mM} \mathrm{NaPi}, 300 \mathrm{mM} \mathrm{NaCl}, 250 \mathrm{mM}$ imidazole, $\mathrm{pH}$ 8.0). Samples from different steps of protein expression and purification (noninduced, 2 hours after induction, 4 hours after induction, lysate, pellet, flow-through fractions from purification, eluates) were analysed on an SDS-PAGE to determine which fractions contained the protein of interest. Fractions containing protein of interest were pooled and stored at $-20^{\circ} \mathrm{C}$. 
To remove imidazole from purified proteins, buffer exchange and concentration steps were performed. Protein samples were concentrated with Sartorius Vivaspin 20 ultrafiltration centrifugal tubes (5,000 MWCO). The buffer was exchanged to sodium phosphate buffer $(10 \mathrm{mM}, \mathrm{pH} 7.4)$ such that the residual amount of Buffer B was $\sim 5 \%$. Protein samples were frozen in liquid nitrogen before storing at $-20^{\circ} \mathrm{C}$. Concentration and final yield of DCD-1L were calculated from fusion protein concentration based on the hypothetical molecular mass ratio between the DCD-1L peptide and the fusion protein.

\subsection{Ulp1 digestion for cleaving His6x and Smt3 tag from DCD-1L}

Purified recombinant proteins containing His6x tag and Smt3 tag were cleaved with Ulp1 protease. $50 \mu \mathrm{l}$ of recombinant protein mixture was incubated with $0.5 \mu \mathrm{l}$ Ulp1 for 10-30 minutes at room temperature, after which the enzyme was heat inactivated for 10 minutes at $65{ }^{\circ} \mathrm{C}$. Samples from cleaved and uncleaved proteins were analysed on $15 \%$ SDS-PAGE to verify the successful digestion.

\subsection{Characterization of the purified recombinant peptide DCD-1L}

Masses of purified peptides were identified with MALDI-TOF-TOF mass spectrometry. Salt was removed from Ulp1-digested DCD-1L peptide with ZipTip. Peptide samples and calibration standards were mixed with a final concentration of $10 \%$ acetic acid. Matrix was prepared for peptides by dissolving a pinch of $\alpha$-cyano-4-hydroxycinnamic acid in a 7:3mixture of deionized water and acetonitrile, and adding trifluoroacetic acid in a final concentration of $0.05 \%$. Matrix was mixed thoroughly by vortexing for $\sim 10$ minutes. $1 \mu \mathrm{l}$ of peptide sample or standard was mixed with $1 \mu \mathrm{l}$ of the matrix on MALDI target plates. The measurement was performed with UltrafleXtream ${ }^{\mathrm{TM}}$ Bruker MALDI-TOF-TOF mass spectrometer equipped with a 200-Hz smart-beam 1 lazer (337 nm, 4 ns pulse). Data collection was carried out by operating the instrument in positive ion mode controlled by the flex software package (FlexControl, FlexAnalysis). 5000 laser shots were accumulated per each spectrum in MS modes. Peptide calibration standard II (Bruker Daltonics) was used to calibrate the MS spectra.

\subsection{Antimicrobial Activity of DCD-1L}

Antimicrobial assays were performed to test the activity of DCD-1L against E. coli DH5 alpha strain. To obtain a standard curve for CFU/ml with respect to different OD600 values, the cells were grown to the desired OD600 values $(0.1,0.2,0.3,0.4,0.5)$ and plated at $1: 10^{6}$ dilution as described previously (Marc and Birgit, 2015). The plates were incubated at $37^{\circ} \mathrm{C}$ for over 12 hours, and the CFUs corresponding to each OD600 value were calculated from the plates. The experimental E. coli cultures were grown at $37^{\circ} \mathrm{C}$ until OD600 reached 0.05 (corresponding to $1.4 \times 10^{8} \mathrm{CFU} / \mathrm{ml}$ ). Cultures were incubated with antimicrobials (DCD-1L, LL-37, nisin and chloramphenicol at a concentration of $100 \mu \mathrm{g} / \mathrm{ml}$ ) and control (sterile deionized water) at 37 ${ }^{\circ} \mathrm{C}$ with shaking for 40 minutes. After incubation, OD600 values of the cells were measured and corresponding CFU values were determined from the standard curve. The data are represented as the percentage of cells killed. 


\section{Results}

\subsection{Expression of DCD-1L peptides in bacteria}

We aimed to produce and purify DCD-1L in E. coli using the SUMO fusion system. For His6xSmt3-DCD-1L, the expression of the desired protein was observed through SDS-PAGE analysis after 2 hours and 4 hours of induction (Figure 2,3). In Figure 2, protein of interest can be observed in the eluate in lane 8 . Furthermore, the protein was present in the lysate (Figure 2,3, lanes 4) and not in pellet (Figure 2,3, lanes 5), indicating good solubility of the fusion protein.

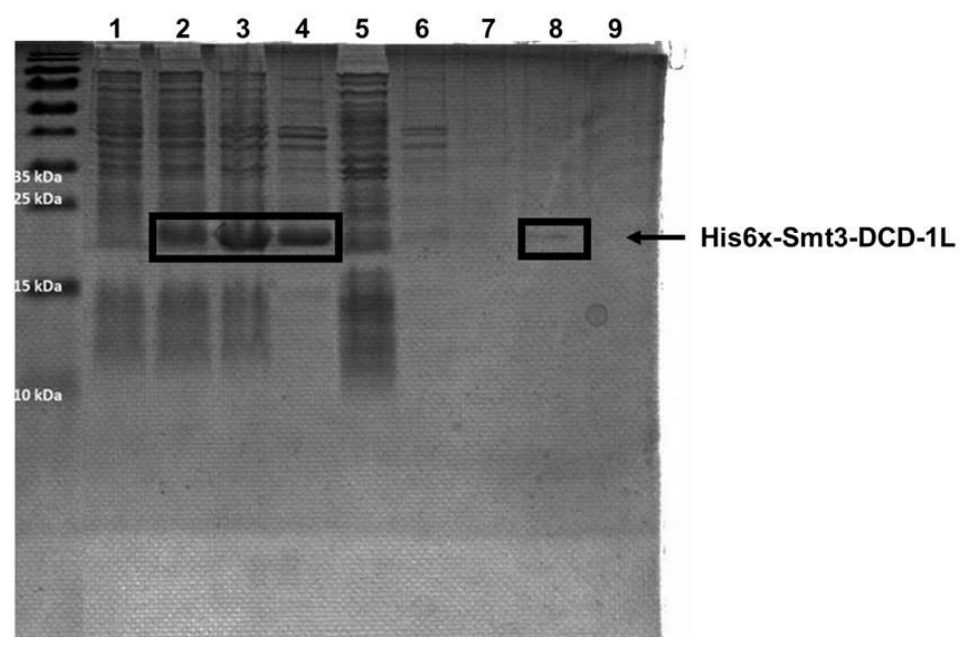

Figure 2. Analysis of His6x-Smt3-DCD-1L small-scale production. The molecular mass of His6xSmt3-DCD-1L is $18.3 \mathrm{kDa}$ and it is indicated in the figure with an arrow. Samples: 1. Smt3-DCD-1L non-induced, 2. Smt3-DCD-1L 2h after induction, 3. Smt3-DCD-1L 4h after induction, 4. Smt3-DCD1L lysate, 5. Smt3-DCD-1L pellet, 6. Smt3-DCD-1L flow-through 1, 7. Smt3-DCD-1L flow-through 2, 8. Smt3-DCD-1L eluate 1, 9. Smt3-DCD-1L eluate 2.

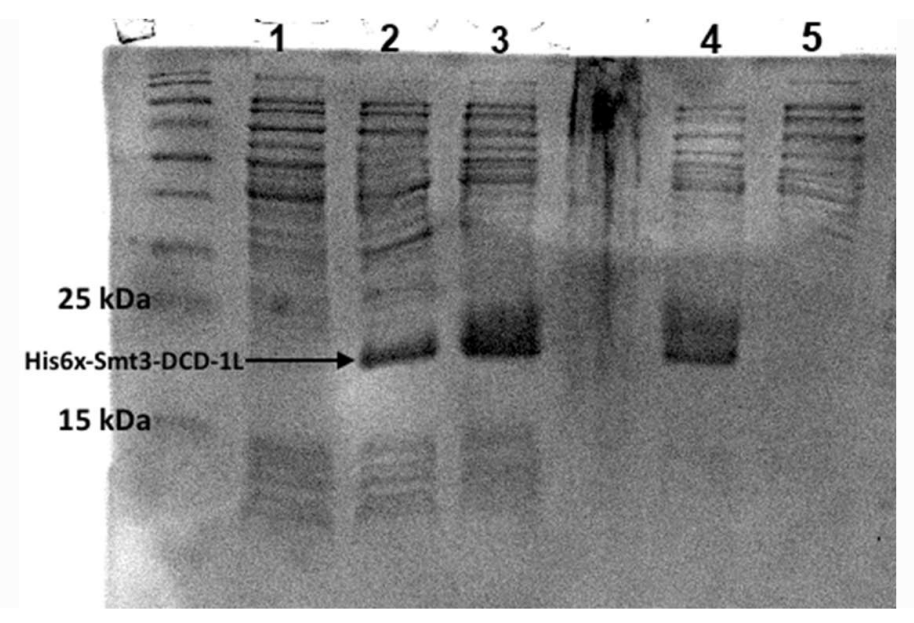

Figure 3. Analysis of His6x-Smt3-DCD-1L larger scale production. Samples: 1. Smt3-DCD-1L noninduced, 2. Smt3-DCD-1L 2h after induction, 3. Smt3-DCD-1L 4h after induction, 4. Smt3-DCD-1L lysate, 5. Smt3-DCD-1L pellet. 
Detection of the intact fusion protein in the SDS-PAGE analysis provided evidence that the SUMO-peptide fusion was protected against cleavage by endogenous proteases. If cleavage had occurred during the purification step, the His6x-Smt3 tag (13.5 kDa) would be observed in the analysis of purified samples (Figure 2,3). Thus, it is clear that no endogenous cleavage interfered with the purification.

\subsection{Purification of peptides}

The His6x-Smt3 tag-based purification of the DCD-1L peptide was successful for smallscale and larger scale culture batches. In Figure 4, the protein of interest can be observed in the eluates, in lanes 1 to 6 corresponding to the molecular mass of His6x-Smt3-DCD-1L which is $18.3 \mathrm{kDa}$.

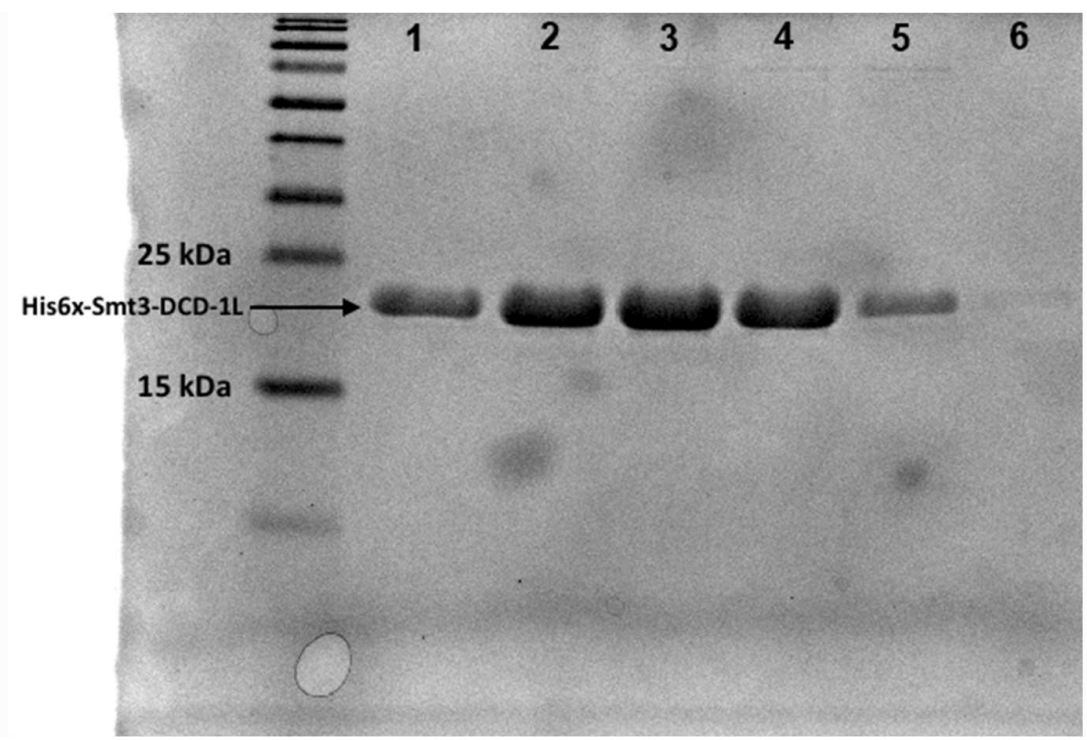

Figure 4. Analysis of the purified His6x-Smt3-DCD-1L. The molecular mass of His6x-Smt3-DCD-1L is $18.3 \mathrm{kDa}$. Samples: 1. Eluate fraction 1, 2. Eluate fraction 2, 3. Eluate fraction 3, 4. Eluate fraction 4, 5. Eluate fraction 5, 6. Eluate fraction 6.

From $500 \mathrm{ml}$ culture, $25.47 \mathrm{mg}$ of purified DCD-1L peptide was obtained after buffer exchange and concentration (Table 1). We anticipate that the construct and production system would likely require optimization to achieve higher yields.

Table 1. Table of final DCD-1L yield.

\begin{tabular}{|l|l|l|l|l|}
\hline $\begin{array}{l}\text { Construct } \\
\text { name }\end{array}$ & $\begin{array}{l}\text { Culture volume } \\
{[\mathrm{ml}]}\end{array}$ & $\begin{array}{l}\text { Purified protein } \\
\text { volume }[\mathrm{ml}]\end{array}$ & $\begin{array}{l}\text { Concentration* } \\
{[\mathrm{mg} / \mathrm{ml}]}\end{array}$ & $\begin{array}{l}\text { Yield } \\
{[\mathrm{mg}]}\end{array}$ \\
\hline DCD-1L & 500 & 9 & 2.83 & 25.47 \\
\hline
\end{tabular}

*concentration of DCD-1L was calculated based on the fusion protein concentration according to the molecular masses of the peptide/fusion protein 


\subsection{Ulp1 enzyme digestion and SDS-PAGE}

To determine a suitable reaction time for digestion of the fusion protein, the digestion reaction was incubated for different time intervals of $0 \mathrm{~min}, 5 \mathrm{~min}$ and $30 \mathrm{~min}$. From Figure 5, it was observed that $5 \mathrm{~min}$ incubation already resulted in the digestion of proteins.

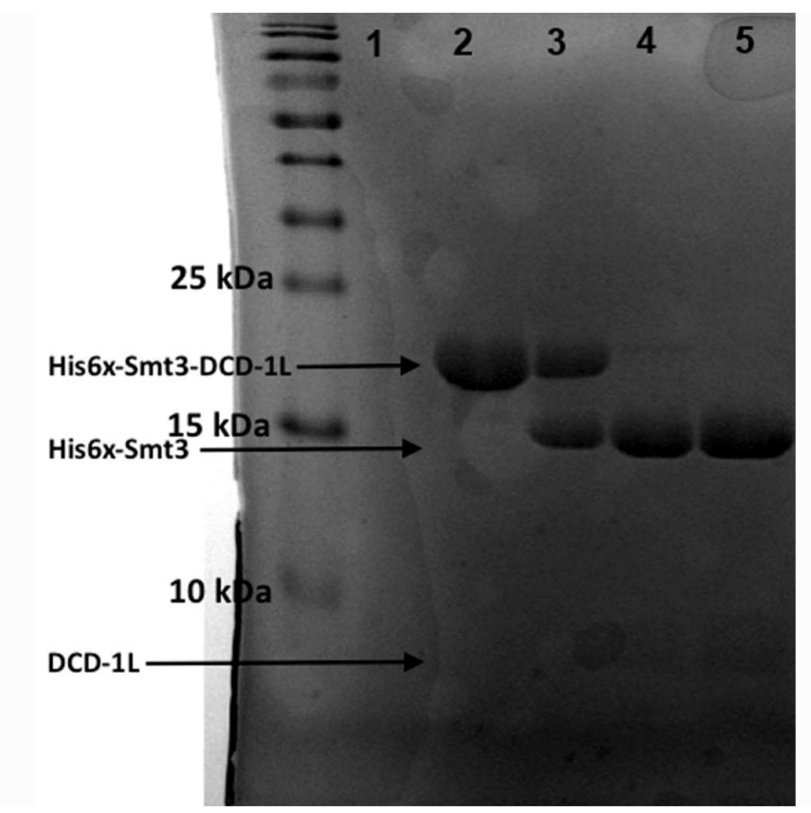

Figure 5. Digestion of His6x-Smt3-DCD-1L with Ulp1. Samples on the gel are: 1. Ulp1 (control), 2. His6x-Smt3-DCD-1L (undigested), 3. His6x-Smt3-DCD-1L + Ulp1 (digested for 1 minutes), 4. His6x-Smt3-DCD-1L + Ulp1 (digested for 5 minutes), 5. His6x-Smt3-DCD-1L + Ulp1 (digested for 30 minutes).

The molecular mass of the DCD-1L peptide is $4.82 \mathrm{kDa}$ and the molecular mass of the undigested fusion protein His6x-Smt3-DCD-1L is $18.3 \mathrm{kDa}$. The digested $\mathrm{N}$-terminus containing the His6x-tag and the Smt3-tag is $13.5 \mathrm{kDa}$ (Figure 5). Due to the small size of DCD-1L peptide, it is challenging to observe the corresponding bands on the SDS-PAGE gel. Instead, the band corresponding to the cleaved N-terminus containing His6x-Smt3 tag was clearly observed from the gel. The image further illustrates that the enzymatic digestion with Ulp1 is very rapid as the digested His6x-Smt3 tag can be clearly distinguished from the undigested protein within few minutes.

\subsection{Identification of purified peptides}

The identity of the peptides was confirmed by mass spectrometry. Following cleavage of expression tags from the fusion protein, DCD-1L peptide was analysed using mass spectrometry. A peak was observed at 4820.434 corresponding to the theoretical mass of DCD-1L peptide (Figure 6). A second peak was observed at 2410.626 and it corresponds to half the mass of the DCD-1L peptide. Given that the result from MALDI-TOF-TOF is mass/charge ratio and the overall charge of DCD- $1 \mathrm{~L}$ is -2 , second peak is a further confirming result. 


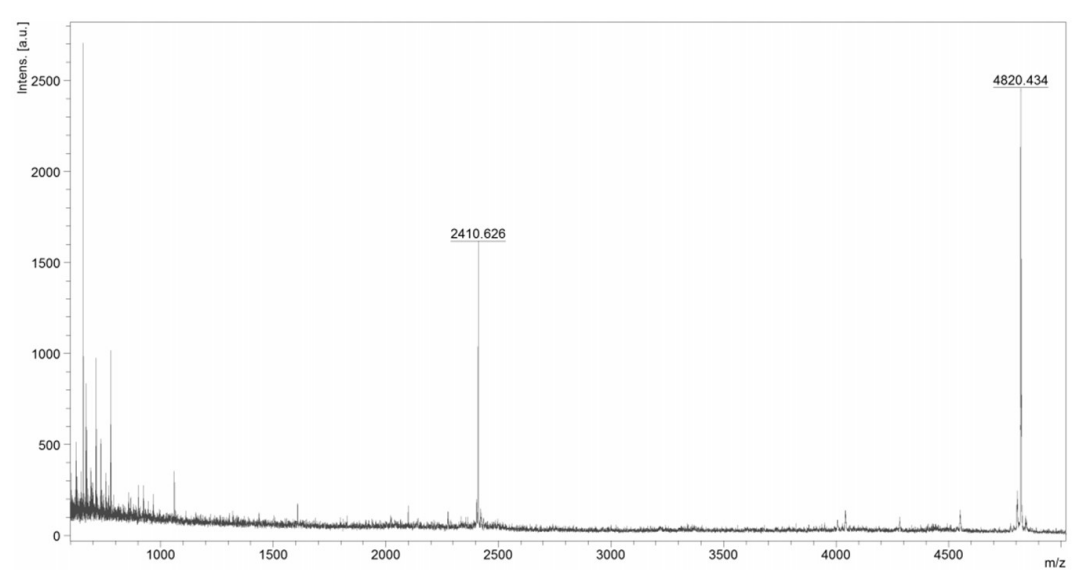

Figure 6. Image of mass spectrometry spectrum for DCD-1L with a peak around 4820.43 Da.

\subsection{Antimicrobial assay}

DCD-1L antibacterial activity along with other antimicrobials (chloramphenicol, nisin and LL-37) was tested against DH5 alpha strain of E. coli. Figure 7 illustrates that DCD-1L inhibited bacterial growth at a comparable level to other well-known antimicrobials, killing $70 \%$ of the cells, while nisin killed $64.28 \%$ and LL-37 $57.85 \%$ of the cells.

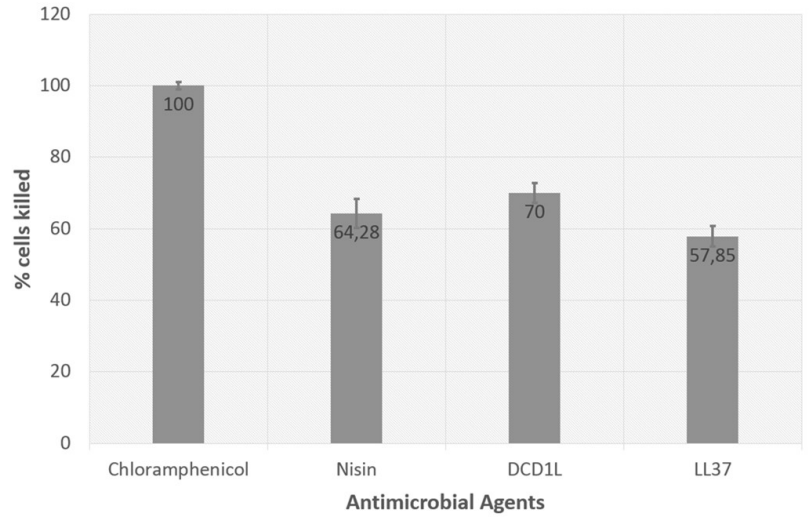

Figure 7. Antibacterial activity of DCD-1L along with Chloramphenicol, Nisin and LL-37 against E. coli DH5 alpha strain after 40 mins of incubation. Antimicrobial activity is represented in terms of percentage of cells killed.

\section{Discussion}

Despite being discovered in 2001, only few production systems for dermcidin have been reported in the literature. The few methods that have been reported for the production and purification of dermcidin are based on the chemical and enzymatic routes to cleave the peptide from its fusion partner. Previously a $\mathrm{CNBr}$ cleavage-based method has been reported for the recombinant production of a 48-amino-acid dermcidin variant with a $\mathrm{C}$-terminal homoserine lactone (DCD-1Hsl) in Escherichia coli, expressed in the form of inclusion bodies (Cipáková 
et al., 2006). Cyanogen bromide, which cleaves C-terminally after methionine, is used extensively, yet it is inefficient in its cleavage (Haught et al., 1998). The presence of methionine within the sequence of many antimicrobial peptides limits its application. In addition, methionines in the carrier or linker region make subsequent purification complicated and less efficient. In the case of the expression of the SUMO-peptide fusion, the fusion protein does not have to be forced into insoluble fractions. On an industrial scale, this could be costly due to the requirement for urea and guanidium chloride to solubilize the inclusion bodies (Lee et al., 2000). Moreover, as observed from our current study, with SUMO system the fusion protein remained in the soluble fraction.

In another study, recombinant MDCD-1L was expressed as an intein fusion protein in E. coli, and then purified by affinity chromatography using chitin beads (Hong et al, 2010). Intein system eliminates the need for exogenous proteases or chemicals that are usually required for tag removal and allows the target peptide to be purified through relatively simple procedures. However, the large size of the intein/chitin domain is a drawback for peptide yield. In addition, uncontrolled autocleavage of the intein fusions even at low levels could be a serious problem as the released antimicrobial peptides can cause fatal effects through direct interaction with their intracellular targets (Díaz et al., 2012). SUMO has been shown to improve folding and its small size $(11.2 \mathrm{kDa})$ allows a relatively high peptide-to-carrier ratio, which favours peptide yield (Li, 2009). In our study, we obtained a yield of $25.47 \mathrm{mg}$ per $500 \mathrm{ml}$ batch of E. coli culture. The urea-resistant property of SUMO is a big advantage as the presence of a small amount of urea can prevent protein aggregation and loosen compact structures, which favours the cleavage ( $\mathrm{Li}, 2011)$.

A highly specific SUMO protease facilitates efficient release of the peptide of interest and leaves no unwanted amino acids at the $\mathrm{N}$-terminus of the peptide after cleavage (Li, 2011). From our mass spectrometry results after Ulp1 digestion, we observed no scar on the peptide. Another important advantage is that this protease is produced cheaply using the T7 driven pET system and can be easily purified with Ni-NTA affinity chromatography similar to the DCD-1L production system and hence, enzymes can be produced in large quantities with relative easiness. In our study, a low amount of enzyme was used for complete cleavage reducing the cost of peptide production. Another study reported the use of factor Xa protease to cleave the fusion protein to produce recombinant DCD-1L (Lai et al., 2005). Comparing with SUMO, factor $\mathrm{Xa}$ is more expensive and sensitive to $\mathrm{pH}$ and chaotropes.

In our study, we observed antimicrobial activity with concentration of $100 \mu \mathrm{g} / \mathrm{ml}$. This is contradictory to the previous studies, where the minimum inhibitory concentration of DCD1L was reported to be $10 \mu \mathrm{g} / \mathrm{ml}$ (Schittek et al., 2001, Steffen et al., 2006). One of the possible reasons for such difference is the E. coli test strain used in this study, which was a cloning strain unlike the ones used in literature. Further comparative antimicrobial activity assays with different bacterial strains need to be performed. One of the current limitations of the study is that data on the activity against other bacterial species are lacking. Thus, the activity of DCD-1L should be studied further against pathogens including Streptococcus and Propionibacterium acnes. Another limitation of the study is that the cleaved tags and the heat inactivated Ulp1 enzyme residues were not removed from our final purified protein products using reversed-phase HPLC before investigating the antimicrobial activity. This limits our ability to obtain reliable results on the antimicrobial activity of our produced peptide. 
Based on different studies it seems to be contradictory whether the presence of salt affects the antimicrobial activity of DCD-1L. The presence of divalent cations (especially $Z n^{2+}$, but also $\left.\mathrm{Mg}^{2+}, \mathrm{Ca}^{2+}\right)$ and monovalent cations $\left(\mathrm{Na}^{+}\right.$has reportedly increased the activity of DCD-1L. It seems to be important for the structure formation of the DCD-1L complex in the bacterial membrane (Paulmann et al., 2012). However, in another study the addition of high concentrations $(100 \mathrm{mM})$ of $\mathrm{NaCl}$ to the buffer was shown to decrease the activity against $E$. coli (Schittek et al., 2001). Thus, we think that the potential contribution of monoand divalent cations to the antimicrobial activity of DCD-1L could be studied further. Hence, further studies need to be carried out to analyse the activity of DCD-1L in different salt and $\mathrm{pH}$ conditions.

\section{Conclusions}

In summary, this work presents an expression and purification method that can be applied to the production of the human anionic antimicrobial peptide DCD-1L in bacteria on large scale. Since DCD-1L is reported to have a wide range of antimicrobial activity and implications in cosmetic industry, we can conclude that this production and purification approach provides a powerful tool for mass production of biologically active DCD-1L in industries. Also, in the future, engineering DCD-1L variants with improved antimicrobial properties have a great potential as antibiotics.

\section{Acknowledgements}

We are grateful to Pezhman Mohammadi at Aalto University for helping with MALDI-TOFTOF mass spectrometry analysis of the peptides and Prof. Per Erik Saris for providing us with valuable inputs about antimicrobial assays. We would like to thank Maisa Vuorte, Meo Ekroos, Matilda Tuure and Michal Pasik from Aalto University and Eveliina Karjalainen and Jenny Mujunen from University of Helsinki for their kind assistance and support in the lab experiments.

\section{References}

Bancovik J, Moreira DF, Carrasco D, Yao J, Porter D, Moura R, Camargo A, Fontes-Oliveira CC, Malpartida MG, Carambula S, Vannier E. Dermcidin exerts its oncogenic effects in breast cancer via modulation of ERBB signaling. BMC cancer. 2015 Dec;15(1):70.

Burian M, Schittek B. The secrets of dermcidin action. International Journal of Medical Microbiology. 2015 Feb 1;305(2):283-6.

Čipáková I, Gašperík J, Hostinová E. Expression and purification of human antimicrobial peptide, dermcidin, in Escherichia coli. Protein Expression and Purification. 2006 Feb $1 ; 45(2): 269-74$.

De Smet K, Contreras R. Human antimicrobial peptides: defensins, cathelicidins and histatins. Biotechnology letters. 2005 Sep 1;27(18):1337-47.

Díaz M, Venturini E, Marchetti S, Arenas G, Marshall SH. Intein-mediated expression of cecropin in Escherichia coli. Electronic Journal of Biotechnology. 2012 Mar;15(2):3-3 
Haught C, Davis GD, Subramanian R, Jackson KW, Harrison RG. Recombinant production and purification of novel antisense antimicrobial peptide in Escherichia coli. Biotechnology and Bioengineering. 1998 Jan 5;57(1):55-61.

Hong I, Kim YS, Choi SG. Simple purification of human antimicrobial peptide dermcidin (MDCD-1L) by intein-mediated expression in E. coli. J Microbiol Biotechnol. 2010 Feb $1 ; 20(2): 350-5$

Kearse M, Moir R, Wilson A, Stones-Havas S, Cheung M, Sturrock S, Buxton S, Cooper A, Markowitz S, Duran C, Thierer T. Geneious Basic: an integrated and extendable desktop software platform for the organization and analysis of sequence data. Bioinformatics. $2012 \mathrm{Apr}$ 27;28(12):1647-9.

Lai YP, Peng YF, Zuo Y, Li J, Huang J, Wang LF, Wu ZR. Functional and structural characterization of recombinant dermcidin-1L, a human antimicrobial peptide. Biochemical and biophysical research communications. 2005 Mar 4;328(1):243-50.

Lee JH, Kim JH, Hwang SW, Lee WJ, Yoon HK, Lee HS, Hong SS. High-level expression of antimicrobial peptide mediated by a fusion partner reinforcing formation of inclusion bodies. Biochemical and Biophysical Research Communications. 2000 Nov 2;277(3):575-80.

Li Y. Carrier proteins for fusion expression of antimicrobial peptides in Escherichia coli. Biotechnology and applied biochemistry. 2009 Sep 1;54(1):1-9.

Li Y. Recombinant production of antimicrobial peptides in Escherichia coli: a review. Protein expression and purification. 2011 Dec 1;80(2):260-7.

Malakhov MP, Mattern MR, Malakhova OA, Drinker M, Weeks SD, Butt TR. SUMO fusions and SUMO-specific protease for efficient expression and purification of proteins. Journal of structural and functional genomics. 2004 Mar 1;5(1-2):75-86.

Milner SM, Ortega MR. Reduced antimicrobial peptide expression in human burn wounds. Burns. 1999 Aug 1;25(5):411-3.

Nakano T, Yoshino T, Fujimura T, Arai S, Mukuno A, Sato N, Katsuoka K. Reduced expression of dermcidin, a peptide active against Propionibacterium acnes, in sweat of patients with acne vulgaris. Acta dermato-venereologica. 2015 Sep 1;95(7):783-6.

Paulmann M, Arnold T, Linke D, Özdirekcan S, Kopp A, Gutsmann T, Kalbacher H, Wanke I, Schuenemann VJ, Habeck M, Bürck J. Structure-activity analysis of the dermcidin-derived peptide DCD-1L, an anionic antimicrobial peptide present in human sweat. Journal of Biological Chemistry. 2012 Mar 9;287(11):8434-43.

Rieg S, Garbe C, Sauer B, Kalbacher H, Schittek B. Dermcidin is constitutively produced by eccrine sweat glands and is not induced in epidermal cells under inflammatory skin conditions. British Journal of Dermatology. 2004 Sep 1;151(3):534-9.

Rieg S, Steffen H, Seeber S, Humeny A, Kalbacher H, Dietz K, Garbe C, Schittek B. Deficiency of dermcidin-derived antimicrobial peptides in sweat of patients with atopic dermatitis correlates with an impaired innate defense of human skin in vivo. The Journal of Immunology. 2005 Jun 15;174(12):8003-10. 
Schittek B, Hipfel R, Sauer B, Bauer J, Kalbacher H, Stevanovic S, Schirle M, Schroeder K, Blin N, Meier F, Rassner G. Dermcidin: a novel human antibiotic peptide secreted by sweat glands. Nature immunology. 2001 Dec;2(12):1133.

Schittek B. The multiple facets of dermcidin in cell survival and host defense. Journal of innate immunity. 2012;4(4):349-60.

Senyürek I, Paulmann M, Sinnberg T, Kalbacher H, Deeg M, Gutsmann T, Hermes M, Kohler T, Götz F, Wolz C, Peschel A. Dermcidin-derived peptides show a different mode of action than the cathelicidin LL-37 against Staphylococcus aureus. Antimicrobial agents and chemotherapy. 2009 Jun 1;53(6):2499-509.

Steffen H, Rieg S, Wiedemann I, Kalbacher H, Deeg M, Sahl HG, Peschel A, Götz F, Garbe C, Schittek B. Naturally processed dermcidin-derived peptides do not permeabilize bacterial membranes and kill microorganisms irrespective of their charge. Antimicrobial agents and chemotherapy. 2006 Aug 1;50(8):2608-20

Steinstraesser L, Koehler T, Jacobsen F, Daigeler A, Goertz O, Langer S, Kesting M, Steinau $\mathrm{H}$, Eriksson E, Hirsch T. Host defense peptides in wound healing. Molecular medicine. 2008 Jul;14(7-8):528.

Yan Y, Orcutt SJ, Strickler JE. The use of SUMO as a fusion system for protein expression and purification. Chem Today. 2009 Nov 1;27(6):42-7. 